\title{
Gastro-intestinal Parasites of Assamese Macaque (Macaca assamensis Hodgson, 1840) in Shivapuri Nagarjun National Park, Kathmandu, Nepal
}

\author{
Geeta Pokhrel ${ }^{1}$ and Mahendra Maharjan ${ }^{2}$ \\ Central Department of Zoology, Tribhuvan University, Kirtipur, Kathmandu, Nepal \\ E-mail: 'Iz.pokharelgeeta@gmail.com \& ${ }^{2}$ Maharjan.m@gmail.com
}

\begin{abstract}
The macaque is a member of the sub family Cercopithecinae and family Cercopithecidae of primate order of mammalian class. Among five species of monkeys reported from Nepal, Assamese Macaque is one of the less common primate species. A total of 85 fresh faecal samples of Assamese Macaque (Macaca assamensis) were collected from Shivapuri Nagarjun National Park (SNNP), Kathmandu, Nepal. All the samples were macroscopically as well as microscopically examined to identify the distribution of gastrointestinal parasites using faecal floatation and Sedimentation techniques. The result revealed the distribution of three species of protozoan and seven species of helminthes parasite among Assamese Macaque of SNNP with the prevalence rate of $72.94 \%$ (62/85). Among protozoan parasites, Balantidium coli showed the highest prevalence (28.24\%) followed by Entamoeba sp. (20\%), and Isospora sp. (3.53\%). Ascaris sp. was found to be distributed maximum (10.58\%) among helminth parasites followed by Trichuris sp. (9.41\%), Strongyloides sp. (8.24\%), Moniezia sp. (8.24\%), Oesophagostomum sp. (4.7\%), Hookworm (4.7\%) and Physeloptera sp.(1.17\%). The present study highlights the necessity of considering parasitic diseases as one of the threat in conservation of Assamese Macaque.
\end{abstract}

Keywords: Assamese macaque (Macaca assamensis), Balantidium coli, conservation, intestinal parasites.

\section{INTRODUCTION}

Primates are the highest order of mammals which includes lemurs, monkeys, apes, human and other similar forms, typically having dexterous hands and feet, binocular vision as well as developed brain (Mary et al. 2007). The macaque is a member of the sub family Cercopithecinae and family Cercopithecidae of primate order of mammalian class. A total of five species of monkeys have been reported from Nepal: Assamese Macaque (Macaca assamensis Hodgson, 1840), Rhesus Macaque (Macaca mulatta Zimmermann, 1780), Terai Grey Langur (Semnopithecus hector Pocock, 1928), Nepal Grey Langur (Semnopithecus schistaceus Hodgson, 1840), and Himalayan Grey Langur (Semnopithecus ajax Pocock, 1928) (Jnawali et al. 2012). Among them Assamese Macaque is one of the less common primate species and is explored patchily in Nepal (Chalise 2010). Macaca assamensis are only sporadically distributed in limited areas of the Nepal, India, Bhutan, Southeast Asia, and China (Wada 2005). In Nepal it has been recorded from $380 \mathrm{~m}$ in Mulghat Tamor to $2350 \mathrm{~m}$ a.s.l. in Langtang (Chalise 2005).

Parasites play a major role in ecosystems (Esch \& Fernandez 1993), host population growth and regulation
(Hochachka \& Dhondt 2000, Hudson et al. 1998), and community biodiversity (Hudson et al. 2002). Both helminth and protozoan parasites are common in nonhuman primates (Munene et al. 1998, Muriuki et al. 1998). Some of the parasites are considered to be nonpathogenic. However, a large number can result in physiologic disturbances, nutritional loss, or may produce lesions that result in serious debilitation, and can create opportunistic for secondary infections that may be fatal (Toft \& Eberhard 1998). In monkeys, disease emergence can occur directly through human introduced diseases or indirectly through human induced changes in the disease ecology of wildlife. This study aims to determine the distribution of intestinal parasites of Assamese Macaque (Macaca assamensis). A few studies of Assamese Macaque have been done on the ecological basis (Wada 2005, Regmi \& Kandel 2008, Pandey 2012) but, the information regarding the gastro- intestinal parasites of Assamese Macaque is still lacking. Hence, the present study has provided information regarding distribution of various protozoan and helminth parasites of Assamese Macaque of SNNP. 


\section{MATERIALS AND METHODS}

A total of 85 faecal samples of monkeys were collected in two seasons: summer (40) and winter (45) of 2012 respectively. During the sample collection, a troop of macaques were systematically followed from dawn to dusk. About 5 gram of fresh samples was carefully collected in sterile sample collection vials with paper marking. All faecal samples were stored in vials containing $2.5 \%$ potassium dichromate solution. Before and after collection, all the faeces were examined macroscopically for consistency, presence of blood or mucus, tapeworm proglottids and adult or larval nematode. In the laboratory, the samples were microscopically examined using concentration techniques viz., faecal floatation and sedimentation.

The samples resulting from the application of these techniques were divided among three different slides, each for a different method using temporary staining (Lugol's iodine) and examined under light microscopy at $10 \mathrm{X} \times 10 \mathrm{X}$ and $40 \mathrm{X} \times 40 \mathrm{X}$ magnification.

\section{RESULTS}

\section{General prevalence of intestinal parasites}

Out of 85 faecal samples examined, 62 samples were found to be positive for either protozoans or helminthes or both parasites showing prevalence rate of $72.94 \%$. The result revealed that a total of 10 different species of gastrointestinal parasites were found to be distributed among Assamese Macaque of SNNP. Distribution of helminth parasites ( 7 species) was found to be higher compared to the protozoan parasites ( 3 species).

\section{Distribution of specific intestinal parasites}

Among the three species of protozoan parasites, $B$. coli showed high distribution in Assamese Macaque of SNNP with prevalence rate of $28.24 \%$ followed by Entamoeba sp. (20\%) and Isospora sp. (3.53\%). Among the seven species of helminthes parasites reported, six species belonged to nematoda and only one species belongs to cestoda. Trematode parasite was not observed in Assamese Macaque of SNNP. Ascaris sp. (10.58\%) was found to be distributed maximum among nematode parasites in these monkeys followed by distribution of Trichuris sp. (9.41\%), Strongyloides sp. (8.24\%), Moniezia sp. (8.24\%), Oesophagostomum sp. (4.7\%), Hookworm (4.7\%) and Physeloptera sp. (1.17\%). While concerning only protozoan parasites, $B$. coli was the highest infective parasite whereas Ascaris $s p$. was the highest infective helminth parasite (Figs. 1 \&2).

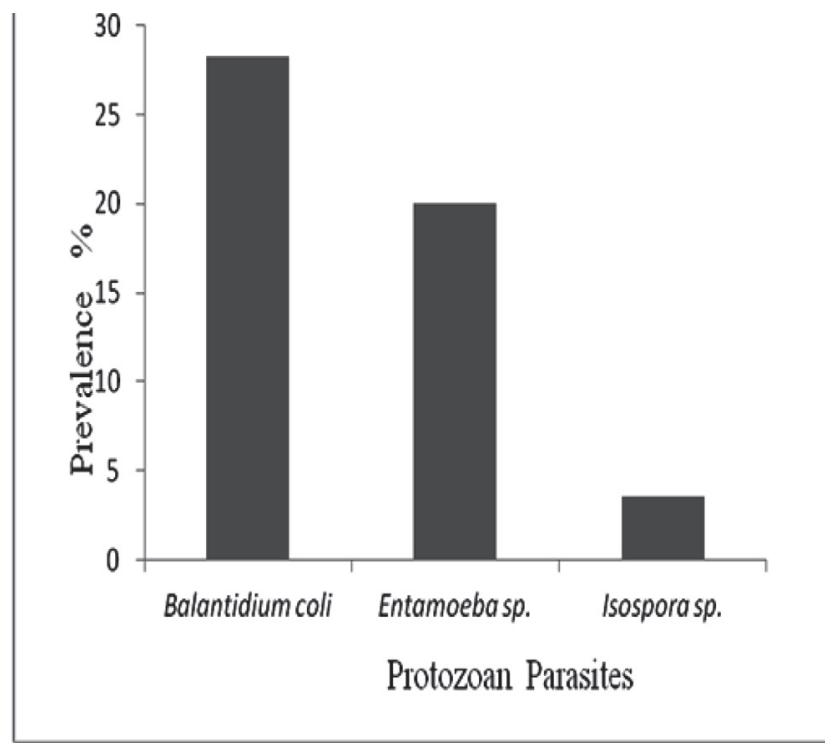

Fig. 1. Prevalence of Protozoan Parasites

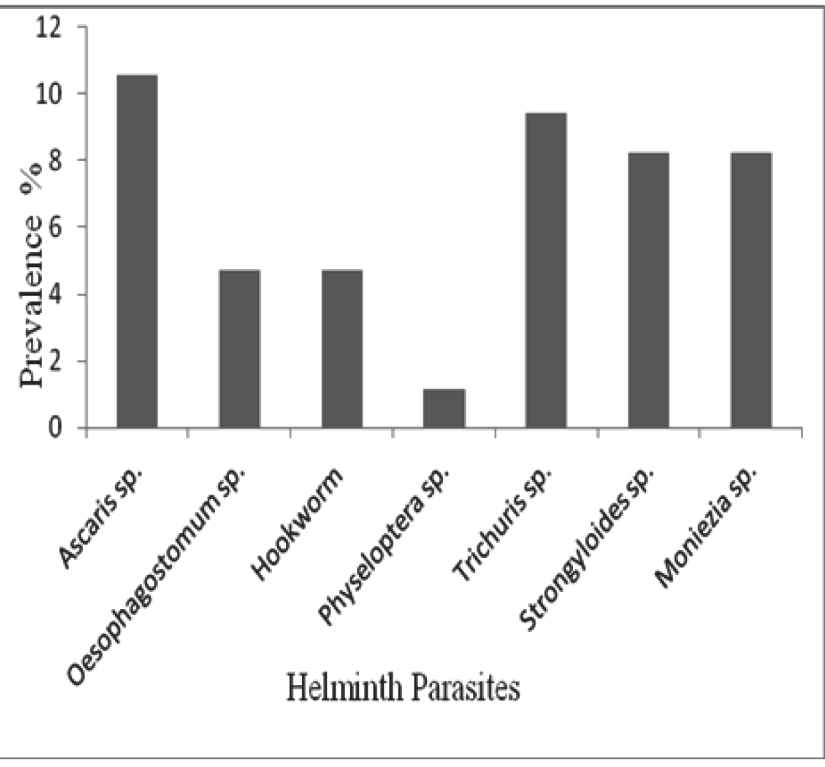

Fig. 2. Prevalence of Helminth Parasites

\section{Concurrency of intestinal parasites}

The result indicated that maximum number of Assamese Macaque suffered from single parasite infection, either protozoan or helminth parasites showing prevalence rate of $43.53 \%$. $15(17.65 \%)$ samples were found to be positive for two parasites. The triple infection by intestinal parasites was $4.7 \%$ and quadruple infection of intestinal parasites in same sample was the least (1.17\%). Only one sample was found infected by four different parasites. Maximum samples with multiple infections were due to combination of both protozoan and helminth parasites (Fig. 3). 


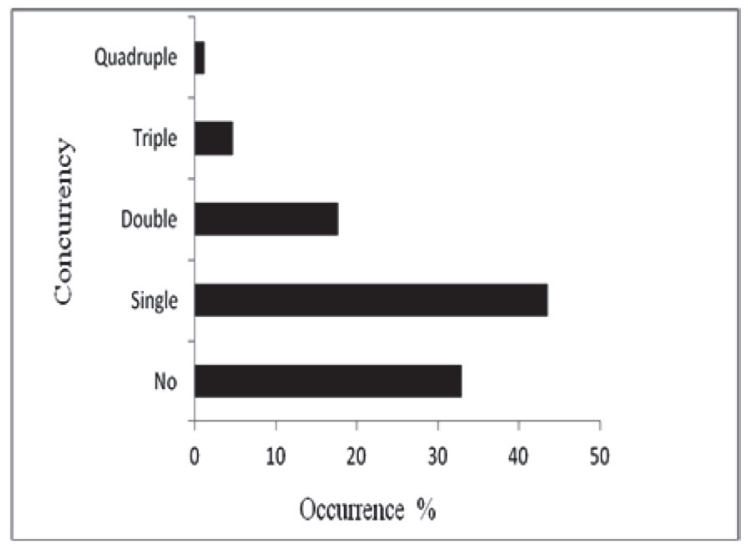

Fig. 3. Concurrency and occurrence of intestinal parasites

\section{DISCUSSIONS}

Assamese Macaque is a less common primate species and is explored patchily in Nepal (Chalise 2010). It is also given the status of Endemic in distribution due to localization in Nepal only (Chalise 2005). The species is confirmed from Kimni Acham, Dadeldhura, Ramdi Palpa, Langtang NP and Helambu area, Makalu-Barun NP and Bhumlingtar, Hariharpur and Nagarjun forests of Kathmandu. They are not recorded from Tarai plain and high snowy mountains and in human settlements (Chalise 2005) although five species of monkeys have been reported from Nepal (Jnawali et al. 2012). Intestinal parasites in Assamese Macaque found in present study resemble that of the previous studies of prevalence of parasites in Macaca assamensis (Wongsawad 2009). The prevalence rate (of $93 \%$ ) reported from feral Bonnet Macaque in India (Varadharajan and Pythal 1999) was the highest prevalence of gastrointestinal parasites reported till now. Previous studies among Rhesus Monkey from different area of Nepal has shown the positivity ranging from 60-85\% (Dhoubhadel 2007, Malla 2007, Nepal 2010) though prevalence rates were seen to vary according to locality. Three protozoan parasites viz: $B$. coli, Entamoeba sp., and Isospora sp. were observed occupying prevalence percentage of $28.24 \%, 20 \%$, and $3.53 \%$ in present study. Similar protozoan parasites were also reported in Macaca assamensis (Wongsawad 2009), in free living Feral Bonnet Macaque (Macaca radiata) elsewhere in the world. B. coli was the predominent intestinal protozoan parasites, whose presence in present study was supported by previous studies $27.5 \%$ and $62 \%$ of balantidial infection in Macaca assamensis and Papio anubis (Wongsawad 2009, Ryan et al. 2012) whereas less prevalence of Balantidium coli was reported in the Bonnet Macaque (Varadharajan \& Pythal 1999) contributing only 6\%. Entamoeba $\mathrm{sp}$. was found to be highly prevalent in Macaca assamensis showing prevalence rate of $87.5 \%$ (Wongsawad 2009). This result is higher than the present study. Isospora sp. has been reported in Macaca radiata and Macaca assamensis (Varadharajan and Pythal 1999, Wongsawad 2009).

The helminth parasites observed in this study were also reported in several previous studies concerning intestinal parasitic infection in Macaca radiata and Macaca mulatta (Varadharajan and Pythal 1999, Eberhard et al. 2001). The prevalence rate of Ascaris sp. was reported indicating 34\% from Macaca radiata (Varadharajan \& Pythal 1999), followed by $10.48 \%$ from Macaca mulatta (Malla 2007) and by $7.45 \%$ from the similar species (Nepal 2010). But in the present study it was found to be $10.58 \%$ from Macaca assamensis. Oesophagostomum sp. was found to be highly prevalent in a Papio anubis (Bezjian et al. 2008) with prevalence rate of $85 \%$ followed by $20 \%$ from Assamese Macaque's (Wongsawad 2009). Some researchers of Nepal suggested low prevalence of Oesophagostomum sp. from Macaca mulatta of different areas ranging from 4-10\% infection rate (Nepal 2010, Dhoubhadel 2007, Malla 2007) while in this study prevalence rate was found to be $4.7 \%$ from Macaca assamensis. Only 4.7\% hookworm was observed in the study. The difference in parasite species might be due to the environmental as well as genetic and behavioural factors. Mutani et al. (2003) documented prevalence rate of Physeloptera sp. to be $58.5 \%$ from Cercopithecus aethiops sabaeus. However, this study showed very low prevalence rate from Macaca assamensis that was $1.17 \%$. In the case of Trichuris sp., previous studies among Rhesus Monkey from different area of Nepal has shown the low positivity ranging from 7-12\% (Dhoubhadel 2007, Malla 2007, Nepal 2010). This result shown is almost similar to the present study. Likewise, only 5\% prevalence of Trichuris sp. was shown from Macaca assamensis (Wongsawad 2009). Wongsawad (2009) found $60 \%$ prevalence rate of Strongyloides sp. from Macaca assamensis. But, in the similar type species (Macaca mulatta and Macaca radiate) the prevalence rate was found $40 \%$ (Dhoubhadel 2007, Varadharajan \& Pythal 1999). It was found to be $13.72 \%$ from Assamese Macaque in this study. The study shows the variation of parasitic distribution as well as their prevalence according to the host as well as locality.

Oesophagostomum sp. and Strongyloides fulleborni were prevalent only in adult female guenon (Gillespie et al. 2004). This may reflect energy and nutrient stress associated with producing and raising infants. However, Strongyloides fulleborni was higher in adult male compared to adult female Red Colobus. Perhaps this reflects energy and nutrient stress associated with maintaining social dominance (Gillespie et al. 2005) 
which may result in an increased susceptibility to infection (Milton 1996). Dunn (1963) reported Moniezia sp. from Wild Howlers (Aloutta sp.). Although Moniezia sp. is the parasite of herbivores, its presence in the monkeys is not uncommon as the monkeys of SNNP are more closely in contact with herbivore animals of that area. It can be concluded from this study that the competitors also affect on the types and prevalence of intestinal parasites on these monkeys.

\section{CONCLUSIONS}

In conclusion the Assamese Macaque of Shivapuri Nagarjun National Park are infected with various protozoan and helminth parasites. Among them Balantidium coli was found to be highly prevalent species compared to other parasites. Test revealed that there was no significant difference in the prevalence of parasites between two seasons. The study highlights the importance of further in depth studies regarding disease aspects of monkeys and their association with their survivability in order to conserve them.

\section{ACKNOWLEDGMENTS}

We are thankful to Department of National Park and Wildlife Conservation (DNPWC) and Shivapuri Nagarjun National Park (SNNP) for permission to conduct the research inside the National Park. We also extend our appreciation to Central Department of Zoology (CDZ) for providing laboratory facilities. Also, our special thanks go to all the staffs of CDZ and associated personnel.

\section{RERERENCES}

Bezjian, M., Gillespie, T.R., Chapman, C.A. and Greiner, E.C. 2008. Coprologic evidence of gastrointestinal helminthes of forest Baboons, Papio anubis, in Kibale National Park, Uganda. Journal of Wildlife Diseases 44(4): 878-887.

Chalise, M.K. 2005. New Characters of Assamese Monkeys in Nepal. Abstract for the National Conference on Animal Taxonomy - Emerging Trends Department of Zoology, Sacred Heart College, Thevara, Kochi-682013 Kerela, India. (January 14-15). Abstract Book.P

Chalise, M.K. 2010. A study of Assamese Monkey in Sebrusbeshi of Langtang National park, Nepal. Journal of Natural History Museum 25: 54-61.

Dhoubhadel, M. 2007. Prevalence of gastrointestinal helminth parasites of Rhesus Monkey (Macaca mulatta) from Shyombhu and Nilbarahi. M.Sc. Thesis. Central Department of Zoology, Tribhuvan University, Kathmandu, Nepal.

Dunn, F.L. 1963. Acanthocephalas and Cestodes of South American monkeys and marmosets. Journal of parasitological 45: 717-722.
Eberhard, M.L., Kovacs-Nace, E., Blotkamp, J., Verwij, J.J., Asigri, V.A. and Polderman, A.M. 2001. Experimental Oesophagostomum bifurcum in monkeys. Journal of Helminthology 75(1): 51-56.

Esch, G. and Fernandez, J.C. 1993. A Functional Biology of Parasitism: Ecological and

Evolutionary Implications. Chapman and Hall, London.

Gillespie, T.R., Greiner, E.C., and Chapman, C.A. 2004. Gastrointestinal Parasites of the guenons of western Uganda. Journal of Parasitology 90(6): 1356- 1360.

Gillespie, T.R., Greiner, E.C. and Chapman, C.A. 2005. Gastrointestinal Parasites of the colobus Monkeys of Uganda. Journal of Parasitological 91(3): 569573.

Hochachka, V.W. and Dhondt, A.A. 2000. Densitydependent decline of host abundance resulting from a new infectious disease. Proceedings of the National Academy of Sciences. United States of America 97: 5303-5306.

Hudson, P.J., Rizzoli, A., Grenfell, B.T., Heesterbeek, H. and Dobson, A.P. 2002. The

Ecology of Wildlife Diseases, Oxford University Press, Oxford, United Kingdom.

Jnawali, S.R., Baral, H.S., Lee, S., Acharya, K.P., Upadhyay, G.P., Pandey, M., et al., 2012

(Compilers).The Status of Nepal's Mammals:

The National Red List Series, Department of NationalParks and Wildlife Conservation, Kathmandu, Nepal.

Malla (Gurung), V. 2007. Intestinal helminth parasites of Macaca mulatta (Zimmermann) from Pashupati (Kathmandu district) and Nilbarahi area (Bhakatapur district) of Nepal. M. Sc. Thesis. Central Department of Zoology, Tribhuvan University, Kathmandu, Nepal.

Mary, T.S., Eric, J.S., Jonathan,I.B. and M.B. 2007. Primate Origins and Supraordinal Relationships: Morphological evidence winfried henke Ian Tattersall editors, Handbook of paleoanthropology. Primate evolution and human origins volume 2 .

Milton, K. 1996. Effects of bot fly (Alouattamyia baeri) parasitism on a free-ranging howler (Alouatta palliata) population in Panama. Journal of Zoology 239: 39-63.

Munene, E., Otsyula, M., Mbaabu, D.A., Mutahi, W.T., Muriuki, S.M. and Muchemi, G.M.1998. Helminth and protozoan gastrointestinal tract parasites in captive and wild trapped African nonhuman primates. Vetenerinary Parasitological 78: 195-201. 
Muriuki, S.M.K., Murugu, R.K., Munene, E., Karere, G.M. and Chai, D.C. 1998. Some gastro-intestinal parasites of zoonotic (public health) importance commonly observed in old world non-human primates in Kenya. Acta Tropica.71: 73-82.

Mutani, A., Rhynd, K. and Brown, G. 2003. A preliminary investigation on the gastrointestinal helminthes of the Barbados green Monkey (Cercopithecus aethiops sabaeus). Revista do institute de medicine tropical sao Paulo 45

Nepal, 2010. Seasonal prevalence of intestinal helminth parasites in Rhesus Monkey (Macaca mulatta) of Swoyambhu area of Kathmandu valley. M. Sc. Thesis. Central Department of Zoology, Tribhuvan University, Kathmandu, Nepal.

Pandey, B.P. 2012. Assamese Macaque in Shivapuri Nagarjun National Park. Population, Distribution and Behavior Study. Shivapuri Nagarjun National park, DNPWC, Government of Nepal.

Regmi, G.R. and Kandel, K. 2008. Population status, threats and conservation measures of Assamese macaque (Macaca assamensis) in Langtang National Park, Nepal. A report submitted to Primate Society of Great Britain, UK.
Ryan, S J., Brashares, J. S., Walsh C., Milbers, Kilory, C., and Chapman C.A. 2012 A Survey of gasterointestinal parasites of Olive Baboons (Papio anubis) in human settlement areas of Mole National Park, Ghana. Journal of Parasitological 98(4): 885-888.

Toft, J.D. and Eberhard, M.L. 1998. Parasitic diseases. In: Bennett BT, Abee CR, Henrickson R (eds.). Nonhuman Primates in Biomedical Research Diseases.pp. 111-114, Academic Press, San Diego.

Varadharajan, A. and Pythal, C. 1999. Incidence of gastro-intestinal parasitism in free living,feral Bonnet Macaque (Macaca radiata L.) Case Report. Zoos' Print Journal 14(6): 41-42

Wada K. 2005. The distribution Pattern of rhesus and Assamese Monkeys in Nepal. Primate 46:

Wongsawad, C. 2009. Coprodiagnosis using smear and sedimentation techniques to detect intestinal parasites of Assamese Macaques, Macaca assamensis from Wat Tham- Pla, Chiang Rai Province, Trench Research in Science and Technology 1(1): 65-70. 